\title{
Fungal gold and firewood on the Tibetan plateau: examining access to diverse ecosystem provisioning services within a rural community
}

\author{
Emily Woodhouse, Philip McGowan and E. J. Milner-Gulland
}

\begin{abstract}
Provisioning ecosystem services include wild products that form an integral part of rural economies. Using quantitative and qualitative data from semistructured interviews with 50 households in a Tibetan community in Western Sichuan, China, we explored the relationships of households with three diverse provisioning services on the Eastern Tibetan plateau: firewood, medicinal caterpillar fungus Ophiocordyceps sinensis and matsutake mushrooms Tricholoma matsutake. We examined (1) how they contribute to wealth and livelihoods, (2) what determines household access, and (3) how local use has changed over time. All households were reliant on firewood, and levels extracted were explained only by household size. A more complex set of factors explained access to caterpillar fungus: younger, larger, pastoralist households with lower dependency ratios tended to collect more, and education and household size explained variation in price gained for the product. Caterpillar fungus extraction has dramatically increased over the last 20 years, providing up to $72 \%$ of household income, but poorer households have received significantly less of their income from the fungus. Matsutake contributed much less to livelihoods because of its relatively low price. The results show a contrast between subsistence and market-driven products: access to the latter is affected by competition and power relationships. Overall access to provisioning services was related to facets of wealth, especially human capital. The study contributes a household level analysis of the diverse provisioning value of an underresearched part of the world, highlighting the heterogeneity and dynamism of the relationships of households with ecosystem services.
\end{abstract}

Keywords Access, caterpillar fungus, ecosystem services, firewood, livelihoods, matsutake, non-timber forest products, Tibetan plateau

This paper contains supplementary material that can be found online at http://journals.cambridge.org

Emily Woodhouse (Corresponding author) and E.J. MiLner-Gulland Imperial College London, Silwood Park Campus, Buckhurst Road, Ascot, SL5 7PY, UK. E-mail emily.woodhouse@imperial.ac.uk

Philip McGowan Newcastle University, Newcastle-upon-Tyne, UK

Received 27 February 2012. Revision requested 11 June 2012.

Accepted 25 September 2012. First published online 8 August 2013.

\section{Introduction}

C cosystem services are ecological functions underUpinning human well-being (Daily, 1997), and span regulatory, supporting and cultural services as well as the direct provision of food, timber, water, fibre and medicine (Millennium Ecosystem Assessment, 2005). Provisioning services, including wild products, often termed non-timber forest products (NTFPs), form an integral part of rural subsistence and cash economies around the world (Nepstad \& Schwartzman, 1992). Growing commercialization of some wild resources, however, has led to an increase in the volume collected and fuelled fears of overexploitation and declining populations (Peters, 1996). Extraction can also lead to habitat degradation and changes in genetic patterns of populations and ecosystem level processes (Ticktin, 2004). On the other hand, ensuring sustainable harvests is beneficial for both human well-being and biodiversity but requires an understanding of relationships between wild products, livelihoods and wealth within communities, and changing patterns of use (Davies \& Brown, 2007).

Although the Tibetan economy is undergoing a rapid transformation away from agriculture towards secondary and tertiary sectors (construction and the service industry; Fischer, 2011), a large proportion of Tibetans in China are rural, and there remain large socio-economic inequalities between rural and urban areas in western regions (Fischer, 2005). Rural Tibetan communities have the highest poverty rates in China according to household income, education and health indicators (UNDP, 2005). According to state figures the per capita mean rural income in Tibet was c. USD 425 vs the national mean of USD 708 in 2004 (Fischer, 2008; CNY converted to USD Purchasing Power Parity), although rural incomes are increasing in many Tibetan areas. In the last 2 decades the rural cash economy of Tibetan regions has been bolstered by a fungal gold rush in medicinal caterpillar fungus Ophiocordyceps sinensis and matsutake mushrooms Tricholoma matsutake. In 2004 caterpillar fungus contributed $8.5 \%$ of the GDP of the Tibetan Autonomous Region, exceeding the mining industry (Winkler, 2009). Although this trade and the livelihoods of rural Tibetans have been documented (Goldstein et al., 2003; Arora, 2008; Winkler, 2008a), there has been no quantitative analysis of the role of wild products as provisioning services for Tibetan households within rural communities.

People's livelihoods are not just dependent on whether an ecosystem service is available in the area but are 
a function of their ability to derive benefits from it, termed access (Ribot \& Peluso, 2003). Access can vary with a number of household level factors, as well as being related to social dynamics and politics; i.e. patterns of ecosystem service use vary within a community (Waylen, 2010). Conventional wisdom holds that poverty and forest resources are intimately related, so that the poorest sections of a community are often the most reliant on forest services as they have fewer alternatives (Belcher et al., 2005). The poor have been found to be more dependent on NTFPs (Mamo et al., 2007; Kamanga et al., 2009) but other studies have shown that middle or wealthy households gain more from the products in absolute and relative terms (McElwee, 2008; Uberhuaga et al., 2012). The relationship can depend on the type of resource (de Merode et al., 2004; Narain et al., 2008), and there may be no relationship at all (Wickramasinghe et al., 1996). Wealth and, conversely, poverty are, however, complex concepts, with multiple dimensions that go beyond income and material assets and vary between communities and cultures. Theories of poverty based on the idea of livelihoods consider wealth to be constructed not only of financial assets but of four other types of capital: social, human, physical and natural (DFID, 1999). Despite the substantial body of knowledge on the relationship between poverty and ecosystem services in tropical forests, few studies have considered the provisioning role of ecosystem services in grassland systems, such as are found on the Tibetan plateau.

Generally NTFPs have been found to play an important part in livelihood strategies as a backup during times of need (McSweeney, 2004). Typically therefore, access to alternative livelihoods such as wage labour and livestock decrease reliance on wild products (McElwee, 2008). However, when a product becomes commercialized, these relationships can change dramatically. For example the commercialization of Moroccan argan oil led to large gains in wealth and social benefits (Lybbert et al., 2011) but boom can be followed by bust because of rapid extraction and changing markets, leaving dependent and poor households vulnerable to further poverty (Belcher \& Schreckenberg, 2007).

Using data from semi-structured interviews we explore the wild provisioning services of the grasslands and forest to households in one Tibetan community. As the most widely used provisioning services, we examine firewood, caterpillar fungus and matsutake mushrooms. By focusing on these products we are able to contrast a purely subsistence resource (firewood) with two commodified resources (matsutake and caterpillar fungus). Based on recall data we evaluate (1) how fungal products are contributing to wealth and livelihoods, (2) what determines household access to provisioning services (the amounts of the resource collected, and the price received for caterpillar fungus), and (3) how local use of provisioning services has changed with time.

\section{Study area}

The study site is a valley in the west of Sichuan Province, an area recognized by conservation organizations for its high level of biodiversity and endemism (Conservation International, 2012). The valley community of Sangdui (Tibetan: Samdo) lies in the northern part of Daocheng County, in the Ganzi Tibetan Autonomous Prefecture, at an altitude of 3,950 m, and comprises four villages and c. 220 households. It is located in the easterly Kham region of ethnographic Tibet, the area on and around the Tibetan plateau historically home to a Tibetan civilization linked by ethnicity, religion and language (Richardson, 1984). The majority of rural Tibetans in this region are both pastoralist (herding cattle) and agriculturalist (growing barley and turnips), with households allocating varying levels of resources between the two livelihood types.

Forest ecosystems are primarily found in the south-east Tibetan plateau, where there are milder climatic conditions. Anthropogenic forest fragmentation has had a long history on the Tibetan plateau and its valleys, which have been cleared for firewood, timber, livestock rearing, agriculture and settlements (Ryavec \& Winkler, 2006). It has been suggested that the survival of oak Quercus spp. in Tibet is threatened by firewood production and livestock grazing (Tang, 2006), and cutting has been identified as a threat to species in the region (Xiang et al., 2007).

Caterpillar fungus is a parasitic fungus found on the grasslands of the Himalayan region and in all but the driest areas of the Tibetan plateau (Winkler, 2009). Its unique morphology is the result of the fungus parasitizing the ghost moth larvae of the genus Thitarodes. The fungus grows inside the larvae, filling it with mycelium, and emerges from the head of the mummified caterpillar in spring. It is known as yartsa gunbu in Tibetan, meaning summer grass, winter worm, reflecting this seasonal process. It is used as a tonic for a wide range of ailments, from fatigue to cancer, but most famously as an aphrodisiac. Although caterpillar fungus has a long history of human use dating from at least the 15th century (Winkler, 2008a), it is only since economic liberalization in China in the early 1980 s that it became widely commodified (Winkler, 2008b). It is now given as a fashionable luxury gift in Chinese cities and the domestic and international markets are booming. The annual production on the Tibetan plateau is estimated to be 85-200 t (Winkler, 2009) and concern has been raised over falling production (Stone, 2008) and the environmental effects of destructive collection methods (Winkler, 2005).

Matsutake has been a prized edible mushroom in Japan for centuries. In Tibetan it is called beshing shamo, meaning oak mushroom, indicating its ectomycorrhizal association with species of oak. It is found in forested areas below 3,200 $\mathrm{m}$ (Zang, 1984). As with caterpillar fungus there has been a dramatic rise in the price since the 1980s, since 
when Japanese companies have been able to access matsutake in western China. Prices are volatile, responding to shifts in supply and demand at regional and global levels (Yeh, 1998). NGOs have promoted sustainable harvesting of the fungus although there is not yet firm evidence of changes in populations or impacts to ecosystems from current harvesting levels (Menzies \& Li, 2010).

\section{Methods}

Interviews were carried out in Sangdui during January-April 2010. The household is the unit of economic activity, including natural resource use, and therefore interviews were conducted at this level, with the head of household or those involved in household decision-making. We selected households by numbering all the houses in the valley, selecting a random number and visiting the corresponding house. The interviews aimed to obtain measurable information on household demographics, natural resource use and livelihoods for statistical analyses but consolidated and enhanced these data with qualitative information through open-ended questions and discussion. Qualitative data focused on the particularities of the household; e.g. its history, income in previous years, livelihood, and changes in resource use. Recall data were for 2009 and the recall period was 1 year. The questions were piloted in six households in a neighbouring valley and then 50 interviews were conducted in Sangdui, one in each household sampled, representing $23 \%$ of the households in the valley. We sampled across the four villages in the valley community and used village as an explanatory variable in statistical models, to account for any differences between them. Interviews were carried out in Kham Tibetan in the respondents' homes, with help from a translator, recorded in agreement with the participants, and translated into English.

To incorporate indigenous ideas of wealth, which may differ significantly from Western ideas and income-based indices (Chambers, 1987), key informants were used to draw up a list of locally relevant indicators of wealth such as house size and ownership of a tractor, which were used in the questionnaire. Based on these indicators households were categorized into three wealth categories: poor $(n=11)$, middle $(n=26)$ and wealthy $(n=13)$, and categories checked with a key informant.

Statistical analyses were carried out using $R \quad v$. 1.14.1 (R Development Core Team, 2011). We used Generalized Linear Models (GLMs) to explore which household variables explained differences in amounts of natural resource extraction and the price of caterpillar fungus. GLMs relax the assumptions of standard linear regression models by allowing the response variable error to follow nonnormal distributions and have non-constant variances
(Crawley, 2007). The first step in using GLMs is to define the error structure of the model. The variable firewood is count data and exhibited Poisson errors. The response variables caterpillar fungus amount and caterpillar fungus price were square root transformed to normalize the distribution before carrying out the analyses, specifying a Gaussian error structure. For the response variable amount of matsutake a mixed compound Poisson-gamma within the Tweedie family of distributions was specified, which has a positive mass at zero and was otherwise continuous (nine households were not collecting any matsutake, and the variable is otherwise positive). The index parameter determining the distribution, $\mathrm{P}$, was specified as 1.52 .

Akaike's Information Criterion (AIC) was used as a basis for model selection. This is a penalized log likelihood that weighs up the trade-off between the number of parameters and the fit of the model. It ensures variables are not deleted prematurely and allows the ranking of a selection of candidate models (Burnham \& Anderson, 2002). Explanatory variables used in the GLMs (Supplementary Table S1) were chosen on the basis of a review of the literature on resource use and livelihoods, preliminary field work at the study site, and an exploration of the data. We explored interactions visually and included them when they were meaningful and seemed to have an effect. We checked co-dependency between variables, and wealth was excluded from models containing other variables because of its strong relationship with many variables.

\section{Results}

\section{Resource extraction}

Evergreen oak Quercus aquifolioides, the most commonly used species for firewood in Sangdui, is coppiced. Government regulations restrict collection to October and to two tractor loads per household per year (the volume of one trailer is $0.72 \mathrm{~m}^{3}$ but wood is stacked to double the height). Thirteen of the 50 respondents reported collecting firewood in other months. The mean amount collected was 2.9 loads per year in $2009(n=50)$; the modal number was 3 loads, with 19 households collecting this amount. Each tractor load costs USD 2.36, and those who collected more than two loads either paid the local government extra money or extracted the wood illegally. Households collected caterpillar fungus for a maximum of 2 months in 2009, from 20 April to 18 June. Since the price started to rise in the $1980 \mathrm{~s}$ not only have more people started collecting but the community has expanded the areas where they collect and the time spent searching. This led to violent clashes over access with a neighbouring community in 2007. Local collectors were aware of spatial and temporal differences in quality of caterpillar fungus, which affected their patterns of 
TABLE 1 Characteristics of households in the three wealth categories.

\begin{tabular}{|c|c|c|c|c|c|c|c|}
\hline $\begin{array}{l}\text { Wealth } \\
\text { category }\end{array}$ & $\begin{array}{l}\text { No. of } \\
\text { households }\end{array}$ & $\begin{array}{l}\text { Mean income } \pm S D \\
(\mathrm{USD})^{1}\end{array}$ & $\begin{array}{l}\text { Mean household } \\
\text { size } \pm S D\end{array}$ & $\%$ herding & $\%$ educated $^{2}$ & $\begin{array}{l}\text { Mean no. of } \\
\text { cattle } \pm S D\end{array}$ & $\begin{array}{l}\text { Mean dependency } \\
\text { ratio }(\%)^{3}\end{array}$ \\
\hline Wealthy & 13 & $2,868 \pm 928$ & $6.4 \pm 1.6$ & 100 & 85 & $33.7 \pm 17.7$ & 53.6 \\
\hline Medium & 26 & $1,232 \pm 517$ & $6.0 \pm 1.4$ & 81 & 42 & $27.2 \pm 17.5$ & 92 \\
\hline Poor & 11 & $818 \pm 505$ & $3.3 \pm 1.6$ & 27 & 55 & $5.6 \pm 5.8$ & 63.6 \\
\hline
\end{tabular}

${ }^{1} \mathrm{CNY}$ have been converted into USD Purchasing Power Parity

${ }^{2}$ Households with one or more members over the age of 16 who have received any formal education

${ }^{3}$ Ratio of dependants to active adults

collection; e.g. later in the season, people generally moved to higher slopes where the mushrooms fruit later. Specimens collected at higher altitude were also considered better quality, whereas those found in forest were less valuable.

During the height of the season people spent up to 10 hours per day scouring the grasslands. When the top of the mushroom is seen the collector uses a small axe to remove the topsoil, which is then replaced. Almost equal numbers of the collectors were male $(53 \%, \mathrm{n}=100)$ and female $(47 \%)$ and $18 \%$ of the collectors were under 16 . On average 404 pieces were collected per household, median $=375$, with a range of $20-1,100$ pieces .

Matsutake has been collected for trade since the mid to late 1980 s and was collected for c. 1 month during July-August in 2009. Local men, women and a small number of children collected the fungus from forest and forest edges, where the fruiting bodies occur in patches. Forty-one of the 50 households collected at least some matsutake in 2009, and the mean amount of matsutake collected per household was $32 \mathrm{~kg}$ (median $20 \mathrm{~kg}$, range $0-150 \mathrm{~kg}$ ).

\section{Relationships between resource collection, wealth and livelihoods}

Wealth was strongly connected with other household variables (Table 1), including income, but did not differ between villages. The mean household annual cash income was USD 1,566 (median USD 1,298, range USD 201-4,719, $\mathrm{n}=50$ ). Wealthier households tended to have greater household sizes and a pastoral livelihood strategy and were more likely to be educated. Mean dependency ratios were highest for medium wealthy households; low ratios of dependants to active adults in poor households are reflective of small household sizes.

Firewood was collected by all households $(n=50)$ for their own use regardless of wealth and livelihoods, and was not sold. The mean percentage of household cash income earned from caterpillar fungus in 2009 was $72 \%$ (median $80 \%, \mathrm{n}=50$ ). There is a significant difference between wealth levels in the proportion of income received from it (Kruskal Wallis $\mathrm{K}=11.90, \mathrm{df}=2, \mathrm{P}<0.05$; Fig. 1). Poor households received significantly less $(52 \%)$ of their

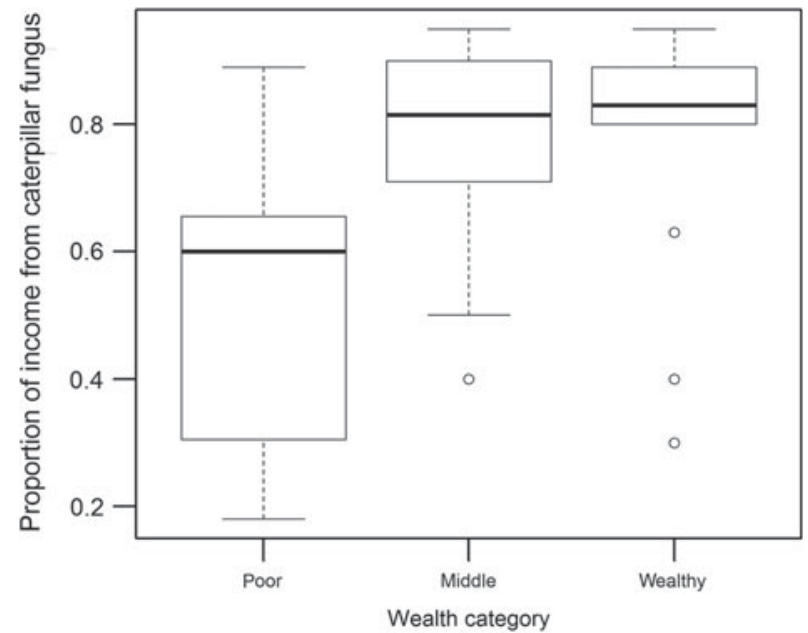

FIG. 1 Proportion of household income gained from caterpillar fungus in 2009, by wealth category. The box indicates the lower and upper quartiles, the line in the box shows the median value, and the ends of the vertical lines indicate a maximum of 1.5 multiplied by the inter-quartile range. Circles show outlying data points.

smaller income from the fungus but instead received a greater proportion from government subsidies and casual labour, mainly construction work. Three of 13 wealthy households earned $<70 \%$ of their income from caterpillar fungus, earning the rest from herding and other professions. The mean percentage of household income from matsutake is $6.0 \%$ (median $4.8 \%, \mathrm{n}=50$ ) and is similar between wealth classes (poor 7.6\%; medium 5.5\%; wealthy 5.6\%).

\section{Determinants of access to provisioning services}

The variables herding, household size, income and village were included in the GLM to explain variation between households in firewood extracted (Supplementary Table S2). One household collecting 10 tractor loads of firewood was omitted from the analysis, as the majority of the wood was used for a death ritual and therefore the value was anomalous. The difference in AIC values between the models was not significant so we carried out model averaging on the models with delta values $<_{5}$ (a delta value is a measure of the support for each model relative 
TABLE 2 Summary of the minimum adequate model explaining the amount of caterpillar fungus Ophiocordyceps sinensis collected in 2009. High dependency was taken as the baseline condition. Overall model: $\mathrm{n}=50, \mathrm{~F}=4.8, \mathrm{df}=6, \mathrm{P}<0.001, \mathrm{R}^{2}=0.401$, adjusted $\mathrm{R}^{2}=0.318$.

\begin{tabular}{lrlrl}
\hline & Estimate & SE & \multicolumn{1}{l}{$t$} & $\mathrm{P}$ \\
\hline Intercept & 6.196 & 5.543 & 1.118 & 0.270 \\
Age & -0.194 & 0.083 & -2.347 & $0.024^{*}$ \\
Dependency (low) & 8.458 & 2.762 & 3.062 & $0.004^{* *}$ \\
Dependency (medium) & 6.949 & 2.642 & 2.630 & $0.012^{*}$ \\
Herding (yes) & 15.277 & 5.442 & 2.807 & $0.007^{* *}$ \\
Household size & 3.260 & 0.875 & 3.726 & $0.001^{* * *}$ \\
Herding (yes) : Household & -2.927 & 1.042 & -2.809 & $0.007^{* *}$ \\
$\quad$ size & & & & \\
\hline$* * *<0.001^{* *}, \mathrm{P}<0.01^{*}, \mathrm{P}<0.05$ & & &
\end{tabular}

to the best model) to determine which variables appeared to be most important. Household size is the most important (weighted model average 0.58), followed by income (0.40), herding (0.23) and village (0.14). Ownership of a tractor to collect wood did not affect the amount of firewood collected. Nine households that did not own a tractor relied on cash to hire someone, social relationships to borrow a tractor, and other economic transactions such as exchange labour.

Given that the cash economy in this community was heavily dependent on caterpillar fungus, household income was not included in the model for amount collected, to avoid circularity. The variables included were herding, age, education, land, alternative work, dependency ratio, household size, village and the interaction between household size and herding (Supplementary Table $\mathrm{S}_{3}$ ). There is strong support for the first model (the delta AIC for the next model is $>2$ ) and it was taken as the minimum adequate model, with parameter estimates given in Table 2. The model suggests that households with a younger household head, lower dependency ratios, more members, and a herding livelihood strategy tend to collect more caterpillar fungus. The interaction between herding and household size also explains some variation: for nonherding households, caterpillar fungus extraction increased with household size but within herding households the relationship was negative.

The mean price obtained for caterpillar fungus varied between households. Those that were able to send a household member to sell the fungus in Sangdui town received a higher price, whereas fungus sold on the mountain at the point of collection was generally cheaper. Quality differs between specimens and changes through the season; attributes indicating quality are hardness, a yellow colour, and large size of the larval host. Specimens collected at higher altitudes were considered higher quality, so those collectors able to travel further were at an advantage. The average
TABLE 3 Summary of minimal model for price of caterpillar fungus received in 2009. Overall model: $\mathrm{n}=50, \mathrm{~F}=7.225, \mathrm{df}=2$, $\mathrm{P}<0.01, \mathrm{R}^{2}=0.2352$, adjusted $\mathrm{R}^{2}=0.2026$.

\begin{tabular}{lrlrc}
\hline & Estimate & $\mathrm{SE}$ & \multicolumn{1}{l}{$t$} & $\mathrm{P}$ \\
\hline Intercept & 2.86121 & 0.17674 & 16.189 & $<0.001^{\star * *}$ \\
Household size & 0.10074 & 0.03023 & 3.333 & $0.00168^{* *}$ \\
Education none & -0.26193 & 0.11505 & -2.277 & $0.0274^{*}$ \\
\hline
\end{tabular}

***, $<0.001 ;{ }^{* *}, \mathrm{P}<0.01 ; *, \mathrm{P}<0.05$

TABLE 4 Summary of minimal model for mushrooms Tricholoma matsutake collected in 2009. Overall model: $\mathrm{n}=50, \mathrm{P}<0.001$, $\mathrm{df}=2, \mathrm{~F}=2.014 \times 10^{4}, \%$ deviance explained $=11 \%$.

\begin{tabular}{lclrc}
\hline & Estimate & SE & $t$ value & $\mathrm{P}$ \\
\hline Intercept & 3.8696 & 0.22721 & 17.031 & $<0.001^{* * *}$ \\
Wealth (poor) & -0.02333 & 0.41836 & -0.056 & 0.9558 \\
Wealth (wealthy) & 0.85438 & 0.34669 & 2.464 & $0.0174^{\star}$
\end{tabular}

$* * *,<0.001 ; *, \mathrm{P}<0.05$

reported price received per piece in 2009 was USD 2.60 (median 2.36, range 1.42-4.25). A GLM was run to explore which household factors explain differences in the mean price received between households in 2009 (Supplementary Table S4). The explanatory variables herding, village, education, household size and dependency were included in the maximal model. The first two models have similar AIC values so both models have considerable support. However, the model summary for the second model shows that herding does not explain a significant amount of variation $(P=0.2)$, and so the first model is the more parsimonious minimal model (Table 3). Larger households and those with educated adults were able to obtain a better price for the fungus.

Wealth was initially not included in the maximal model for the amount of matsutake collected because of correlations with other variables. According to AIC values the null model was the best but when wealth was included in the model on its own, there was strong support for this model $(\triangle \mathrm{AIC}=3.71)$, with wealthy households collecting significantly more matsutake than other households (Table 4).

\section{Changes in resource collection over time}

For each of the three products, respondents most often reported they were collecting less in 2009 than 5 years previously but the reasons given were different for each. For firewood the most common reason given was that there are fewer trees available because many have been cut (12 respondents). Five respondents said they collected less because of government restrictions. Fourteen households said they collected the same amount as before, and only two reported more collection, because of greater need. 
Over a longer time period people suggested they collected a greater amount of firewood following the use of motorized vehicles.

Of the 28 out of 50 respondents who reported a decline in caterpillar fungus collected, the majority said it was because of the weather, and in particular a lack of rain. The second most common reason given was greater competition for the product and fewer pieces found per household. Only two people thought they could now collect more fungus, and nine said that the amount fluctuates annually because of the weather and therefore they could not judge overall.

Twenty-nine of the 50 respondents reported collecting fewer matsutake mushrooms, largely because the price had declined. This was also the explanation given by those households who chose not to collect any matsutake in 2009. As with caterpillar fungus, the crop fluctuates according to the weather, in particular with levels of precipitation.

\section{Discussion}

The community has use rights over the ecosystem provisioning services in this case study, yet there is differential access between households, which affects local patterns of service use. Household size was the most important variable explaining differences in firewood collected, probably because bigger households need more heating and cooking fuel. Some studies have suggested a negative correlation between income and firewood collection (Sharma et al., 2009). Here there was simply no alternative to firewood so that all households were reliant on it to a greater or lesser extent, and income was needed to pay the local government for the wood. Nonetheless, social relationships were an important means of access for some poorer households with no means to transport firewood.

In contrast, access to caterpillar fungus was related to a more complex set of factors. Firstly, households with a younger household head are not only likely to have fitter and healthier family members with a greater ability to collect the fungus, which relies on labour capacity, but also have more incentive to accumulate wealth to build up their household asset base (McSweeney, 2004). Demographic variables are not static and the data show a snapshot of the community in one particular stage of its life cycle. But households grow, shift livelihoods, suffer mortality and are therefore in a dynamic relationship with the surrounding environment (Perz \& Walker, 2002). Livelihood type was also a significant factor; those households that herded cattle tended to collect more caterpillar fungus. Pastoralists are likely to have better access to and knowledge of the grasslands where the fungus grows. Tibetans use subsistence occupations based on provisioning services as a strong livelihood base for coping with uncertainty (Fischer, 2008). This strategy not only highlights the capabilities of the rural poor in meeting their livelihood needs through diversification (Ellis, 2000) but that the caterpillar fungus trade is being adeptly integrated into pastoralism, a livelihood connected to historicallyrooted Tibetan identities (Yeh \& Gaerrang, 2011)

Access is not only about being able to physically collect a natural resource but to use and sell it to gain benefits. Those with bigger households were more likely to be able to send someone into town to sell the fungus for a better price, and those with a member who was numerate and literate had an advantage in negotiating a higher price. The ability to speak Mandarin is also necessary for business with Chinese traders, a skill obtained largely through formal schooling. Herders and those with large family sizes can respond to the high levels of competition for caterpillar fungus by travelling further afield and at higher altitudes, to reach high quality specimens.

Although commodified, matsutake mushrooms, in comparison to caterpillar fungus, were contributing little to household incomes in 2009 and there was not such a clear explanation for differences in access. Broadly, the wealthy were collecting significantly more but there was little difference between households in the contributions to income made by the matsutake trade. Nine out of the 50 households were not collecting the fungus, mainly because they did not view it as sufficiently profitable, and there had been a shift in allocation of resources away from the product. The matsutake market is volatile, and it appears that as the market conditions change, people respond in different ways. Most were investing a small amount of household resources in collection but there was no notable pattern of access with household variables.

The relationship a household has with the environment is mediated by different kinds of capital (De Sherbinin et al., 2008). Overall, we found that access to provisioning services was related to particular facets of wealth that in turn align with different types of capital: social, human, physical and financial. Wealth was strongly correlated with demographic factors, including education, household size and dependency ratio. For the provisioning ecosystem services in the local environment, human capital in the form of labour availability, education and knowledge was the most important factor in household access. Social relationships and cultural factors related to the pastoralist lifestyle were also significant.

Sale of caterpillar fungus was contributing on average $72 \%$ of household income in 2009 , corroborating previous studies in the region (Winkler, 2008a), and more broadly the high reliance on NTFPs in the Himalayan region (Rijal et al., 2011). This case study contradicts the common notion that NTFPs provide natural insurance during times of need (Pattanayak \& Sills, 2001); rather, caterpillar fungus now constitutes the core of almost all household income in the community. There is a difference between wealth classes, 
however, with the poor gaining less income from the fungus. Poverty, which is related to lack of access to ecosystem services, is pushing certain households into jobs such as construction, which are socially undesirable compared to herding, trade and artisanal crafts. Although there is some circularity involved in these relationships, so that access to caterpillar fungus was a means and end to wealth, elements of poverty were also barriers to access. In this way wealth, income and access to ecosystem services are in a mutual yet dynamic relationship.

The initial enthusiasm for enhancing access to NTFPs as a conservation and development tool has been tempered by concerns of elite capture by the wealthiest sections of society (Dove, 1994) or, conversely, by evidence that it leads to the perpetuation of poverty (Neumann \& Hirsch, 2000). The poor are left with low-value goods that they cannot use as a route out of poverty, whereas the affluent can benefit from commercialized products (Vira \& Kontoleon, 2010). These ideas do not hold completely true for this case study. Although there was differential access, the poor were still gaining significantly because absolute barriers to service use were not present and capital-rich households could not completely monopolize the market, suggesting that the caterpillar fungus trade is alleviating poverty. In addition, firewood was accessed by all households out of necessity. Given the heavy dependence on the fungus, a decline in harvest rates or price would be potentially catastrophic for the whole community. Likewise, conservation regulations (such as restrictions on access to the montane grasslands) would affect the income of all households. Only a minority appeared to be able to access other skilled labour markets through education, as in other Tibetan areas (Fischer, 2005).

The ecological effects of provisioning ecosystem service extraction depend on a variety of factors, including frequency and intensity of collection, timing, size of specimens and the technique used, as well as specific context (Ticktin, 2004; Belcher et al., 2005). Generally the greater the intensity of collection, the greater the ecological effects will be. Firewood collection appears to have increased over a long time period because of improved transport but the general trend during the last 5 years is unclear from these data. Some respondents reported that resource scarcity and increased government restrictions had decreased collection but illegal removal of firewood appears common. There is no doubt that intensity of caterpillar fungus collection has increased dramatically in the last 20 years, along with spatial expansion, and there is little or no regulation at the study site. But there is no clear evidence, or even expectation, of negative ecological effects on the target species, given that the fungus is itself a parasite causing mortality of the original host. Hence the effects of harvesting, mediated through a highly weather-dependent parasite-host relationship, are likely to be complex. Of more concern may be the indirect ecosystem effects of large numbers of people spending substantial amounts of time digging and living in fragile ecosystems. Winkler (2009) draws attention to the unreliable data used in studies showing a dramatic fall in overall production over time but this does not preclude a cautious approach to maintaining the sustainability of harvesting, especially given currently high livelihood dependence on the fungus. Limiting collection seasons so that adequate fungal sporulation is maintained may be one conservation measure (Winkler, 2009). However, given the ecological and social complexities involved further research is warranted before embarking on conservation actions.

The data used in the study were limited in several respects. Estimates of household income from recall data over 1 year are likely to be underestimated (Rayamajhi et al., 2012), and the use and value of resources vary annually because of climatic and economic changes (Cavendish, 2000). We attempted to overcome these problems by discussing income season by season during household interviews, to improve accuracy of estimates, and including qualitative data regarding indigenous wealth and changes in resource availability across the community but a longitudinal study using repeat measures of income and natural resource use would be of value. There may not only be heterogeneity at the household scale but at the village level (McSweeney, 2002) and this case study will not be completely representative of other communities in the region. However, the collection of caterpillar fungus and matsutake is widespread across the Tibetan and Himalayan region, so that although the results would not be replicated exactly because of variation in climate, wealth and other factors, they have relevance, especially for Tibetan communities in China.

This study demonstrates the diverse provisioning value of the grassland and forest ecosystems on the Tibetan plateau. It contributes to an emerging body of knowledge on the value of ecosystem services to the rural poor through a case study in a region of the world that has received little attention. In particular, the results contrast a purely subsistence necessity resource, firewood, with a highly commodified and profitable medicinal grassland fungus that has more complex issues of access reflecting high levels of competition, power and human capital as well as its widespread grassland habitat. Our focus on access draws attention to the heterogeneity of communities, and the dynamic relationships between households, their natural environments, and the provisioning ecosystem services that these environments provide. The value of these services is influenced by household life cycles and the broader socio-economic context in which communities are embedded. Conservation and development initiatives must address these complexities and be aware of the high dependence of livelihoods on provisioning services in this area. 


\section{Acknowledgements}

We thank Dr Wang Nan and Beijing Forestry University, and our field assistants Tashi Rabden, Pema Dechin, Tsewang Chomtso and Gele Chopel for their invaluable help, the Forest Bureau of Daocheng county for permission and support, and the people of Sangdui for their hospitality and participation. The research was funded by the ESRC and the World Pheasant Association. EJMG acknowledges the support of a Royal Society Wolfson Research Merit Award.

\section{References}

Arora, D. (2008) The houses that matsutake built. Economic Botany, $62,278-290$

Belcher, B., Ruíz-Pérez, M. \& Achdiawan, R. (2005) Global patterns and trends in the use and management of commercial NTFPs: implications for livelihoods and conservation. World Development, 33, 1435-1452.

Belcher, B. \& Schreckenberg, K. (2007) Commercialisation of non-timber forest products: a reality check. Development Policy Review, 25, 355-377.

Burnham, K.P. \& Anderson, D.R. (2002) Model Selection and Multimodel Inference: a Practical Information-Theoretic Approach. Springer-Verlag, New York, USA.

Cavendish, W. (2000) Empirical regularities in the poverty-environment relationship of rural households: evidence from Zimbabwe. World Development, 28, 1979-2003.

Chambers, R. (1987) Sustainable Livelihoods, Environment and Development: Putting Poor Rural People First. IDS, Brighton, UK.

Conservation International (2012) Biodiversity hotspots: Mountains of Southwest China. Http://www.conservation.org/ where/priority_areas/hotspots/asia-pacific/Mountains-ofSouthwest-China/Pages/default.aspx [accessed 19 January 2012]. Crawley, M.J. (2007) The R Book. Wiley Blackwell, Oxford, UK.

D AILy, G.C. (1997) Nature's Services: Societal Dependence on Natural Ecosystems. Island Press, Washington, DC, USA.

Davies, G. \& Brown, D. (2007) Bushmeat and Livelihoods: Wildife Management and Poverty Reduction. Blackwell Publishing, Oxford, UK.

de Merode, E., Homewood, K. \& Cowlishaw, G. (2004) The value of bushmeat and other wild foods to rural households living in extreme poverty in Democratic Republic of Congo. Biological Conservation, 118, 573-581.

De Sherbinin, A., VanWey, L.K., McSweeney, K., Aggarwal, R., Barbieri, A., Henry, S. et al. (2008) Rural household demographics, livelihoods and the environment. Global Environmental Change, 18, 38-53.

DFID (Department for International Development) (1999) Sustainable Livelihoods Guidance Sheets. Http://www.eldis.org/vfile/ upload/1/document/o901/section2.pdf [accessed 19 January 2012].

Dove, M. (1994) Marketing the Rainforest:'Green' Panacea or Red Herring? Asia Pacific Issues, East-West Center, Honolulu, USA.

Ellis, F. (2000) Rural Livelihoods and Diversity in Developing Countries. Oxford University Press, Oxford, UK.

Fischer, A.M. (2005) State Growth and Social Exclusion in Tibet: Challenges of Recent Economic Growth. University of Hawaii Press, Honolulu, USA.
Fischer, A.M. (2008) Subsistence and rural livelihood strategies in Tibet under rapid economic and social transition. International Association of Tibetan Studies Journal, 4, 41-49.

Fischer, A.M. (2011) The great transformation of Tibet? Rapid labour transitions in times of rapid growth in the Tibetan Autonomous Region. Himalaya, The Journal of the Association for Nepal and Himalayan Studies, 30, 63-78.

Godoy, R., Groff, S. \& O’Neill, K. (1998) The role of education in neotropical deforestation: household evidence from Amerindians in Honduras. Human Ecology, 26, 649-675.

Goldstein, M.C., Jiao, B., Beall, C.M. \& Tsering, P. (2003) Development and change in rural Tibet: problems and adaptations. Asian Survey, 43, 758-779.

Kamanga, P., Vedeld, P. \& Sjaastad, E. (2009) Forest incomes and rural livelihoods in Chiradzulu District, Malawi. Ecological Economics, 68, 613-624.

Lybbert, T.J., Aboudrare, A., Chaloud, D., Magnan, N. \& NASH, M. (2011) Booming markets for Moroccan argan oil appear to benefit some rural households while threatening the endemic argan forest. Proceedings of the National Academy of Sciences, 108, 13963-13968.

Mamo, G., Sjaastad, E. \& Vedeld, P. (2007) Economic dependence on forest resources: a case from Dendi District, Ethiopia. Forest Policy and Economics, 9, 916-927.

McElwee, P.D. (2008) Forest environmental income in Vietnam: household socioeconomic factors influencing forest use. Environmental Conservation, 35, 147-159.

McSweeney, K. (2002) Who is 'forest-dependent'? Capturing local variation in forest-product sale, Eastern Honduras. Professional Geographer, 54, 158-174.

MCSWEENEy, K. (2004) Forest product sale as natural insurance: the effects of household characteristics and the nature of shock in Eastern Honduras. Society and Natural Resources, 17, 39-56.

Menzies, N. \& Li, C. (2010) One eye on the forest, one eye on the market: multi-tiered regulation of matsutake harvesting, conservation and trade in Northwestern Yunnan Province. In Wild Products Governance: Finding Policies that Work for Non-Timber Forest Products (eds S. Laird, R. McLain \& R. Wynerg), pp. 243-264. Earthscan, London, UK.

Millennium Ecosystem Assessment (2005) Ecosystems and Human Well-being: Synthesis. Island Press, Washington, DC, USA.

Narain, U., Gupta, S. \& Van't Veld, K. (2008) Poverty and resource dependence in rural India. Ecological Economics, 66, 161-176.

Nepstad, D.C. \& Schwartzman, S. (1992) Non-Timber Products from Tropical Forests: Evaluation of a Conservation and Development Strategy. New York Botanical Garden, New York, USA.

Neumann, R.P. \& Hirsch, E. (2000) Commercialisation of Non-timber Forest Products: Review and Analysis of Research. Center for International Forestry Research, Bogor, Indonesia.

Olsen, C.S. \& Larsen, H.O. (2003) Alpine medicinal plant trade and Himalayan mountain livelihood strategies. Geographical Journal, 169, 243-254.

Pattanayak, S.K. \& Sills, E.O. (2001) Do tropical forests provide natural insurance? The microeconomics of non-timber forest product collection in the Brazilian Amazon. Land Economics, 77, 595-612.

Perz, R. T. \& Walker, R. T. (2002) Household life cycles and secondary forest cover among small farm colonists in the Amazon. World Development, 30, 1009-1027.

Peters, C. M. (1996) Observations on the sustainable exploitation of non-timber tropical forest products. In Non-Timber Forest Products from Tropical Forests: Evaluation of a Conservation 
and Development Strategy (eds D.C. Nepstad \& S. Schwartzman), pp. 19-39. New York Botanical Garden, New York, USA.

R Development Core Team (2011) R: A Language and Environment for Statistical Computing. R Foundation for Statistical Computing, Vienna, Austria.

Rayamajhi, S., Smith-Hall, C. \& Helles, F. (2012) Empirical evidence of the economic importance of Central Himalayan forests to rural households. Forest Policy and Economics, 20, 25-35.

Riвot, J.C. \& Peluso, N.L. (2003) A theory of access. Rural Sociology, $68,153-181$.

Richardson, H.E. (1984) Tibet and its History. Shambhala, Boulder, USA.

Rijal, A., Smith-Hall, C. \& Helles, F. (2011) Non-timber forest product dependency in the Central Himalayan foot hills. Environment, Development and Sustainability, 13, 121-140.

Ryavec, K. \& Winkler, D. (2006) Logging impacts to forests in Tibetan areas of Southwest China: a case study from Ganze Prefecture based on 1998 Landsat TM imagery. Himalaya, The Journal of the Association for Nepal and Himalayan Studies, 26, $39-45$.

Sharma, C.M., Gairola, S., Ghildiyal, S.K. \& Suyal, S. (2009) Forest resource use patterns in relation to socioeconomic status. Mountain Research and Development, 29, 308-319.

STONe, R. (2008) Last stand for the body snatcher of the Himalayas? Science, 322, 1182

TANG, C.Q. (2006) Evergreen sclerophyllous Quercus forests in northwestern Yunnan, China as compared to the Mediterranean evergreen Quercus forests in California, USA and northeastern Spain. Web Ecology, 6, 88-101.

TickTin, T. (2004) The ecological implications of harvesting non-timber forest products. Journal of Applied Ecology, $41,11-21$.

Uberhuaga, P., Smith-Hall, C. \& Helles, F. (2012) Forest income and dependency in lowland Bolivia. Environment, Development and Sustainability, 14, 3-23.

UNDP (United Nations Development Programme) (2005) China Human Development Reports: Development with Equity. China Translation and Publishing Corporation, Beijing, China.

Vira, B. \& Kontoleon, A. (2010) Dependence of the poor on biodiversity: which poor, what biodiversity? In Linking Biodiversity, Conservation \& Poverty Alleviation: a State of Knowledge Review. CBD Technical Series No. 55, pp. 13-28. Secretariat of the Convention on Biological Diversity, Montreal, Canada.

WAlker, R. (2003) Mapping process to pattern in the landscape change of the Amazonian frontier. Annals of the Association of American Geographers, 93, 376-398.
WAy LEN, K. (2010) The implications of local views and institutions for the outcomes of community-based conservation. $\mathrm{PhD}$ thesis. Imperial College London, London, UK.

Wickramasinghe, A., Pérez, M.R. \& Blockhus, J.M. (1996) Non-timber forest product gathering in Ritigala Forest (Sri Lanka): household strategies and community differentiation. Human Ecology, 24, 493-519.

WINKLER, D. (2005) Yartsa gunbu-Cordeceps sinensis: economy, ecology and ethno-mycology of a fungus endemic to the Tibetan plateau. In Wildlife and Plants in Traditional and Modern Tibet: Conceptions, Exploitations and Conservation. Memorie della Società Italiana di Scienze Naturali e del Museo Civico di Storia Naturale di Milano, Vol. 33 (eds A. Boesi \& F. Cardi), pp. 69-85. Società Italiana di Scienze Naturali, Milan, Italy.

WinkLER, D. (2008a) The mushrooming fungi market in Tibet exemplified by Cordyceps sinensis and Tricholoma matsutake. Journal of the International Association for Tibetan Studies, 4, 41-47.

WinkleR, D. (2008b) Yartsa gunbu (Cordyceps sinensis) and the fungal commodification of Tibet's rural economy. Economic Botany, 62, 291-305.

Winkler, D. (2009) Caterpillar Fungus (Ophiocordyceps sinensis) production and sustainability on the Tibetan Plateau and in the Himalayas. Asian Medicine, 5, 291-316.

XIANG, Z.F., Huo, S., WANG, L., Cui, L.W., XIAO, W., Quan, R.C. \& TAI, Z. (2007) Distribution, status and conservation of the black-and-white snub-nosed monkey Rhinopithecus bieti in Tibet. Oryx, 41, 525-531.

Yen, E.T. (1998) Forest Products, Foreign Markets, and Conflict between Tibetan Mushroom Harvesting Villages in Southwest China. Center for Southeast Asia Studies, University of California, Berkeley, USA.

Yeh, E.T. \& Gaerrang (2011) Tibetan pastoralism in neoliberalising China: continuity and change in Gouli. Area, 43, 165-172.

ZANG, M. (1984) Mushroom distribution and the diversity of habitats in Tibet, China. McIlvainea: Journal of American Amateur Mycology, 6, 15-20.

\section{Biographical sketches}

Emily Woodhouse's research spans anthropology and ecology, exploring relationships between people and their environments and focusing on culture, institutions and livelihoods. PHILIP McGowaN is concerned with ensuring that no species of Galliformes go extinct and balancing the needs of all 300 species of Galliformes with those of the communities that live alongside them. E. J. Milner-GULLAnd's research lies at the interface of social and ecological systems, with a particular focus on the conservation of harvested species. Her research group's website is http://www.iccs.org 